\title{
Journal of Mind and Medical Sciences
}

Volume 6 | Issue 1

Article 26

2019

\section{Xanthogranulomatous pyelonephritis: presentation and management}

Răzvan C. Petca

Carol Davila University of Medicine and Pharmacy, Bucharest, Romania

Răzvan I. Popescu

Prof. Dr. Th. Burghele Clinical Hospital, Department of Urology, Bucharest, Romania, dr.razvanp@gmail.com

Cristian Mareș

Prof. Dr. Th. Burghele Clinical Hospital, Department of Urology, Bucharest, Romania

Claudia Mehedințu

Carol Davila University of Medicine and Pharmacy, Bucharest, Romania

Bogdan Mastalier

Carol Davila University of Medicine and Pharmacy, Bucharest, Romania

See next page for additional authors

Follow this and additional works at: https://scholar.valpo.edu/jmms

Part of the Nephrology Commons, and the Pathological Conditions, Signs and Symptoms Commons

\section{Recommended Citation}

Petca, Răzvan C.; Popescu, Răzvan I.; Mareș, Cristian; Mehedințu, Claudia; Mastalier, Bogdan; Badiu, Dumitru Cristinel; Măru, Nicoleta; Constantin, Vlad D.; and Petca, Aida (2019) "Xanthogranulomatous pyelonephritis: presentation and management," Journal of Mind and Medical Sciences: Vol. 6 : Iss. 1 , Article 26.

DOI: $10.22543 / 7674.61 . P 169175$

Available at: https://scholar.valpo.edu/jmms/vol6/iss1/26

This Research Article is brought to you for free and open access by ValpoScholar. It has been accepted for inclusion in Journal of Mind and Medical Sciences by an authorized administrator of ValpoScholar. For more information, please contact a ValpoScholar staff member at scholar@valpo.edu. 


\section{Xanthogranulomatous pyelonephritis: presentation and management}

\section{Cover Page Footnote}

The authors declare that there are no conflicts of interest to be disclosed for this article.

\section{Authors}

Răzvan C. Petca, Răzvan I. Popescu, Cristian Mareș, Claudia Mehedințu, Bogdan Mastalier, Dumitru Cristinel Badiu, Nicoleta Măru, Vlad D. Constantin, and Aida Petca 


\title{
Research article
}

\section{Xanthogranulomatous pyelonephritis: presentation and management}

\author{
Răzvan C. Petca ${ }^{1,2}$, Răzvan I. Popescu ${ }^{2 *}$, Cristian Mareș $^{2}$, Claudia Mehedințu ${ }^{1,3}$, \\ Bogdan Mastalier ${ }^{1,4}$, Dumitru C. Badiu ${ }^{1,5}$, Nicoleta Măru', Vlad D. Constantin', Aida Petca ${ }^{1,6}$ \\ ${ }^{1}$ Carol Davila University of Medicine and Pharmacy, Bucharest, Romania \\ ${ }^{2}$ Prof. Dr. Th. Burghele Clinical Hospital, Department of Urology, Bucharest, Romania \\ ${ }^{3}$ Malaxa Clinical Hospital, Department of Obstetrics and Gynecology, Bucharest, Romania \\ ${ }^{4}$ Colentina Clinical Hospital, Department of General Surgery, Bucharest, Romania \\ ${ }^{5}$ Bagdasar-Arseni Clinical Emergency Hospital, Department of General Surgery, Bucharest, Romania \\ ${ }^{6}$ Elias Emergency University Hospital, Department of Obstetrics and Gynecology, Bucharest, Romania
}

\begin{abstract}
Xanthogranulomatous pyelonephritis (XGP) is characterized by the presence of lipidladen foamy macrophages with both acute and chronic phase inflammatory cells. The aim of the study is to present our experience about patients with Xanthogranulomatous pyelonephritis. 29 patients were evaluated through a complete anamnesis and the preoperative management included routine blood and biochemical tests, urine culture and renal ultrasound, intravenous urography and computed tomography (CT). All patients underwent open nephrectomy followed by the pathological exam. The main symptoms of these patients were fever and flank pain. Preoperative laboratory tests revealed anemia, leukocytosis and increasing levels of blood urea nitrogen (BUN) and creatinine. Kidney failure was noticed in almost half of the cases. This study succeeded to evaluate the demographic, clinical, biological, surgical and histological characteristics. A pathological diagnosis is mandatory mainly for the evaluation of its coexistence with renal carcinoma.
\end{abstract}

Keywords

Highlights
: Xanthogranulomatous pyelonephritis, urinary tract infection, E. Coli, anemia, leukocytosis, nephrectomy

$\checkmark$ Xanthogranulomatous pyelonephritis (XGP) occurs due to recurrent chronic infection secondary to renal lithiasis and it is frequently underdiagnosed due to its unspecific symptoms which mimic other conditions.

$\checkmark$ CT is considered the imaging technique of choice in the diagnosis of the disease preoperatively and a plethora of CT characteristics have been described so far.

$\checkmark$ A diagnosis of certainty is mandatory to be pathological, which is useful not only in the confirmation of the disease, but also in the evaluation of its coexistence with renal carcinoma.

To cite this article: Petca RC, Popescu RI, Mareș C, Mehedințu C, Mastalier B, Badiu DC, Măru N, Constantin VD, Petca A. Xanthogranulomatous pyelonephritis: presentation and management. J Mind Med Sci. 2019; 6(1): 169-175. DOI: 10.22543/7674.61.P169175 


\section{Introduction}

Xanthogranulomatous pyelonephritis (XGP) is a chronic inflammation of the renal parenchyma, which was first described in 1916 by Schlagenhaufer and it occurs in approximately $1 \%$ of all renal infections. Two major forms can be recognized: diffuse and focal (1). Some authors also describe the segmental xanthogranulomatous pyelonephritis which involves only a segment of the kidney. The diffuse form can be easily confused with a severe abscess or pyonephrosis, while the focal form is called pseudotumoral because it is usually confused with a renal tumor.

It generally occurs due to recurrent chronic infection secondary to renal lithiasis which usually leads to obstruction. The infection is usually associated with Proteus or E. Coli, but Pseudomonas is also frequently involved (2). Other agents identified are Staphylococcus aureus, Candida, Bacteroides, group B Streptococcus or Klebsiella. Although nephrolithiasis is usually present, it is not mandatory for diagnosis. The xanthogranulomatous pyelonephritis behaves like a pseudo tumor capable of local invasion and destruction, starting with the kidney, continuing with perinephric fat and, if left untreated, involving the adjacent retroperitoneal structures $(3,4)$.

Histologically, the condition is characterized by the presence of lipid-laden foamy macrophages with both acute and chronic phase inflammatory cells. Focal abscesses may be present.

In most cases, men are affected less than women, with a female to men ratio of 5:1 (5). Regarding the preoperative diagnosis, XGP is frequently underdiagnosed due to its unspecific symptoms which mimic other conditions such as perinephric abscess, pyelonephritis or renal tuberculosis. There is no single clinical or radiologic element of diagnosis specific to xanthogranulomatous pyelonephritis (6). Symptoms include fever, flank pain, lower urinary tract symptoms, hematuria or weight loss. $30 \%$ of patients presented complications such as paranephric abscess, nephrocolonic or nephrocutaneous fistula (7).

Usually, the transabdominal ultrasound evaluation is used to assess the disease. Signs such as hydronephrosis, less parenchymal tissue, staghorn calculus, often indicate a diffuse form, while there are no specific lesions for a focal form. CT findings are strong indicators that reveal helpful information about local and regional involvement. Nowadays, CT is considered the chosen imaging procedure for the preoperative diagnosis of the disease, numerous CT characteristics having been described so far. The most typical CT features of XGP should be considered: low-density fluid-filled areas within the renal parenchyma and additional elements indicating perinephric extension. Studies describe the MRI evaluation as a sensitive method in identifying lipid-laden foamy macrophages (6).

The treatment for the diffuse form of the disease is usually nephrectomy. For the focal form, patients who have contraindications for surgery or bilateral form of the disease, antibiotics are the key to the treatment if there is any diagnosis based on biopsy or combined cytological and clinical features (8). The prognosis is considered reasonable after the treatment. Death from Xantogranulomatous pyelonephritis is exceedingly rare, although morbidity is substantial. Transitional cell carcinoma located in the renal pelvis has been associated with the disease.

The goal of the study is to present our experience with patients diagnosed with XGP in our clinic and to evaluate the demographic, clinical, paraclinical, surgical and histological characteristics of this series of patients, for a better understanding and knowledge of the disease.

\section{Materials and Methods}

We conducted a retrospective observational study from January 2013 to December 2017 that identified 29 patients diagnosed with XGP histologically confirmed who have been treated in our clinic (9). Moreover, patients with Xanthogranulomatous pyelonephritis associated with renal carcinoma have also been included. All patients were evaluated through a complete anamnestic and a rigorous physical exam. Preoperative management included routine blood tests and biochemical urine tests, summary and urinalysis (10). Also, all patients underwent renal ultrasound, intravenous urography and computerized tomography - Figure 1. Patients with low excretory functions at the intravenous urography underwent renal scintigraphy with Tc99m-DTPA to confirm the non-functioning kidney and to evaluate the function of the other kidney. Any urinary tract infection was treated with antibiotics before the surgical intervention, or depending on the severity of the case, the patients underwent percutaneous nephrostomy or Cook stent (double JJ stent) insertion.

The parameters considered were: age, sex, complete blood tests, urine tests, symptoms at presentation such as fever and pain location, affected sides, surgical method and pathological exam. All collected data were analyzed and interpreted using Microsoft Word 2013 and Microsoft Excel 2013. Simple descriptive statistics were calculated (11-13). 


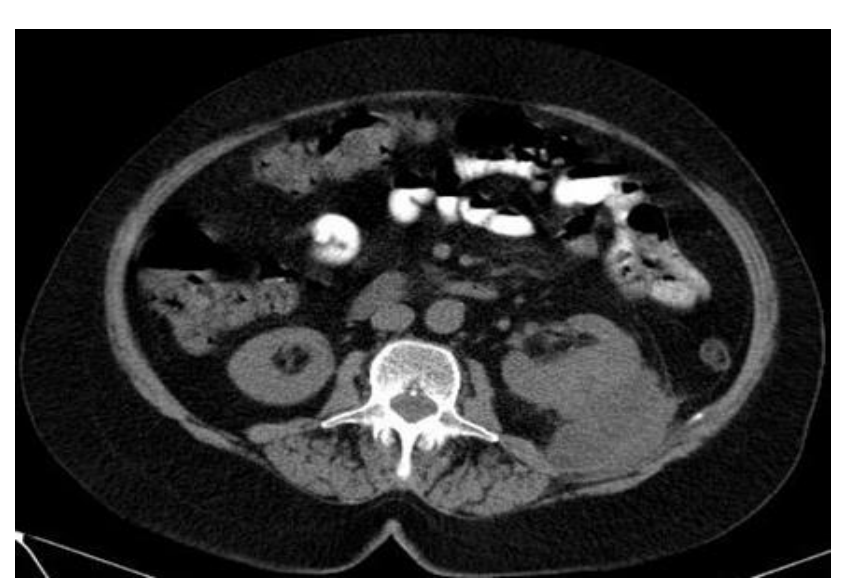

\section{Results and Discussions}

The statistical analysis of our database comprising 29 patients treated in our hospital revealed that there were 25 women $(86.2 \%)$ and only 4 men $(13.8 \%)$, with a female to male ratio of $6.1: 1$, with a mean age of 54.93 years Table 1. More than a half $(51.72 \%)$ were aged between 40 and 60 , over one third (37.93\%) between 60 and 80 and only $10.34 \%$ were aged under 40 , similar results being reported in a study performed in Argentina (14).

Table 1. Patients Characteristics

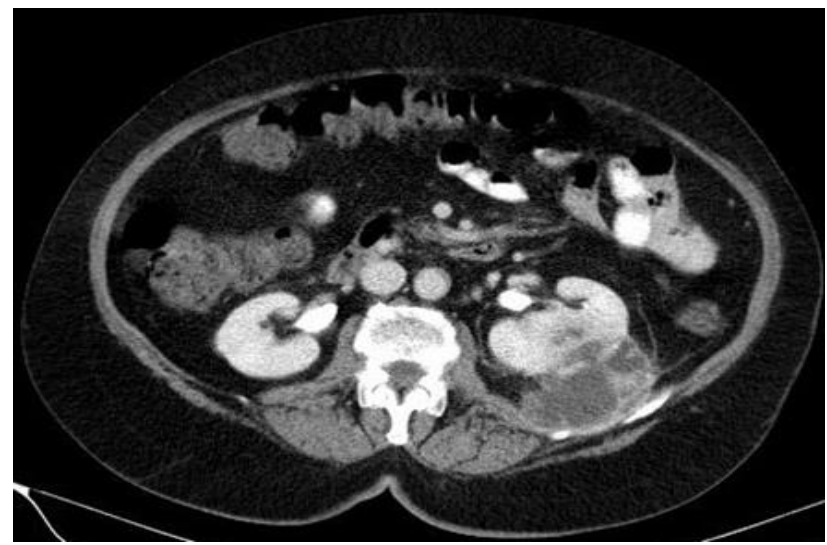

Figure 1. CT pelvic scans in a patient with xathogranulomatous pyelonephritis highlighting the invasion of the disease

All patients underwent nephrectomy, followed by the pathological exam in order to confirm the diagnosis. The tissue samples were placed in formaldehyde and then hematoxylin eosin stain was used for microscopical observations. The diagnosis of XGP was made due to the presence of diffuse or focal inflammatory processes with lipid-laden macrophages and chronic granulomatous inflammation - Figure 2. Postoperatively, the lab tests were repeated and the patients were carefully monitored.

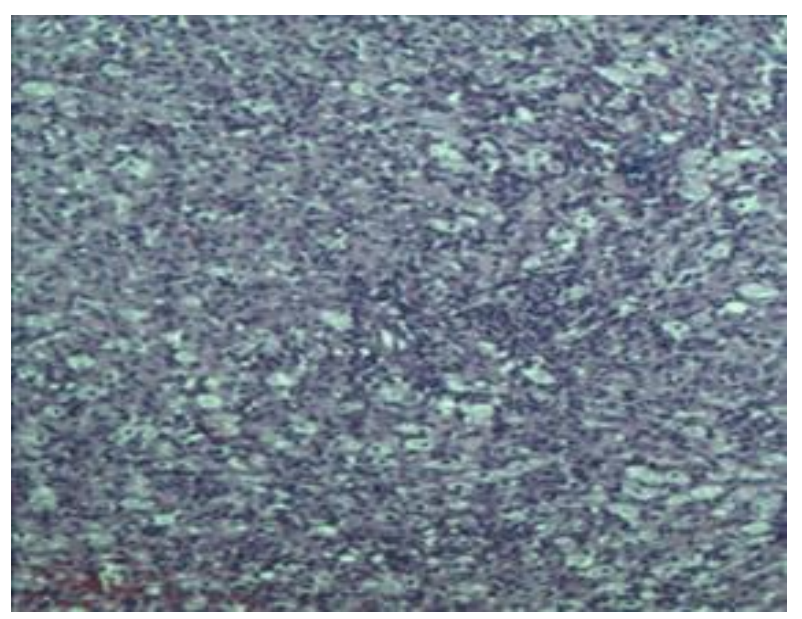

Figure 2. The pathological examination of XGP made from inflammatory lymphoplasmocitary infiltrate and abundant xantomate cell, HE stain

\begin{tabular}{|c|c|c|c|c|}
\hline \multicolumn{3}{|l|}{ Mean Age } & \multicolumn{2}{|c|}{54.95 years } \\
\hline & & & $\%$ & no \\
\hline \multirow[t]{2}{*}{ Sex } & \multicolumn{2}{|l|}{ M } & $13.79 \%$ & 4 \\
\hline & \multicolumn{2}{|l|}{$\mathrm{F}$} & $86.2 \%$ & 25 \\
\hline \multirow[t]{4}{*}{ Symptoms } & Fever & Yes & $55.17 \%$ & 16 \\
\hline & & No & $44.82 \%$ & 13 \\
\hline & $\begin{array}{l}\text { Flank } \\
\text { Pain }\end{array}$ & Yes & $89.65 \%$ & 26 \\
\hline & & No & $10.34 \%$ & 3 \\
\hline \multirow{2}{*}{$\begin{array}{l}\text { Associated } \\
\text { lithiasis }\end{array}$} & \multicolumn{2}{|l|}{ Yes } & $72.41 \%$ & 21 \\
\hline & \multicolumn{2}{|l|}{ No } & $27.58 \%$ & 8 \\
\hline \multirow[t]{2}{*}{ Affected side } & \multicolumn{2}{|l|}{ Left } & $44.82 \%$ & 13 \\
\hline & \multicolumn{2}{|l|}{ Right } & $55.17 \%$ & 16 \\
\hline \multirow[t]{2}{*}{ Urine culture } & \multicolumn{2}{|l|}{ Positive } & $62.06 \%$ & 18 \\
\hline & \multicolumn{2}{|c|}{ Negative } & $37.93 \%$ & 11 \\
\hline
\end{tabular}

As many authors consider, the main symptoms are flank pain and fever. In our study, unilateral flank pain was the main presentation symptom $(89.65 \%)$ followed by fever $(55.17 \%)$. In more than a half $(51.72 \%)$ of the patients, flank pain and fever coexisted at first presentation. Close values are found in related studies (2). The pain of XGP is not colicky in nature; it is usually dull and persistent (15).

In the following chart, we noted that the main symptom for which patients were admitted to our hospital was a combination of fever and flank pain in 15 cases, flank pain in only 11 cases, two of them being asymptomatic and one presenting fever only - Figure 3 .

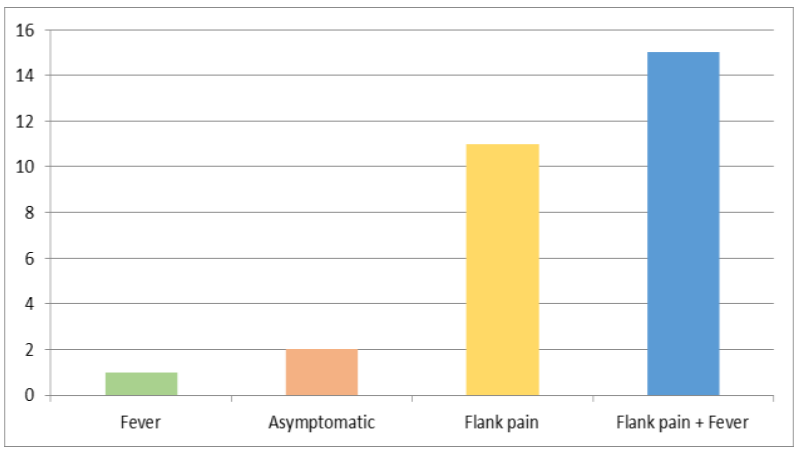

Figure 3. Column chart representing the patients' symptoms at presentation 
Preoperative lab test revealed anemia in 19 patients, leukocytosis in 15 patients and increasing levels of blood urea nitrogen and creatinine in 13 cases. The mean hemoglobin value before surgery was $11.5 \pm 1.9 \mathrm{~g} / \mathrm{dL}$, and the mean value of leukocytes was $10.6 \pm 3.6 \mathrm{x}$ $103 / \mu \mathrm{L}$. One mechanism of anemia suggested by Goodman and co. (16) would be a defect in the reutilization of iron.

As shown in Table 2, the simultaneous presence of anemia and leukocytosis was noticed in more than one third of the patients, but also a high number of patients did not present anemia nor leukocytosis.

A creatinine increase over $1.0 \mathrm{mg} / \mathrm{dL}(\mathrm{F})$ and over 1.2 $\mathrm{mg} / \mathrm{dL}(\mathrm{M})$ was detected preoperatively in 13 patients $(44.82 \%)$. The mean level of creatinine was $1.03 \pm 0.26$ $\mathrm{mg} / \mathrm{dL}$, and the mean level of GFR was $63 \pm 18$ $\mathrm{mL} / \mathrm{min} / 1.73 \mathrm{~m} 2$. Kidney failure was noticed in 13 $(44.82 \%)$ out of the 29 cases with a GFR $<60$ $\mathrm{mL} / \mathrm{min} / 1.73 \mathrm{~m} 2$, but more than half of the patients $(55.17 \%)$ presented normal kidney function.

Table 2. Modifications of the complete blood count

\begin{tabular}{|l|c|c|}
\hline Modifications & no & $\%$ \\
\hline $\begin{array}{l}\text { Anemia \& } \\
\text { Leukocytosis }\end{array}$ & 11 & 37.93 \\
\hline Only Anemia & 8 & 27.59 \\
\hline $\begin{array}{l}\text { Only } \\
\text { Leukocytosis }\end{array}$ & 4 & 13.79 \\
\hline $\begin{array}{l}\text { Neither } \\
\text { Anemia nor } \\
\text { Leukocytosis }\end{array}$ & 6 & 20.69 \\
\hline
\end{tabular}

The urine culture was positive in 18 patients $(62.06 \%)$ and negative in over one third of them (37.84\%). In 16 out of the 18 cases with positive urine culture, a Gramnegative microorganism from the Enterobacteriaceae family was detected, while Gram-positive microorganisms were detected in only two cases (6.89\%). Our findings are consistent with those reported by a study conducted in Greece (17), in terms of the urine culture results.

As shown in the following column chart - Figure 4, the most frequent microorganism identified was E. Coli, followed by Proteus, Klebiella, Enterococcus and Staphylococcus, while a significant number of patients had sterile urine.

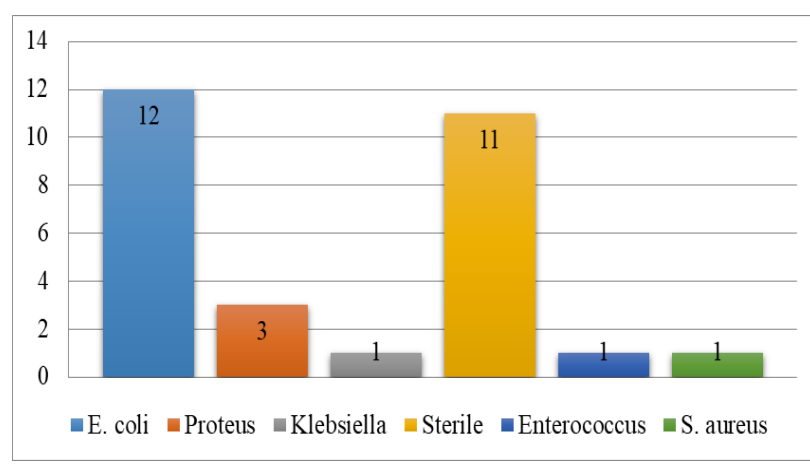

Figure 4. The distributions of the uropathogens identified in urine cultures

In the following column chart - Figure 5, the strong relationship between renal lithiasis and/or urinary tract infections in association with Xanthogranulomatous pyelonephritis is represented.

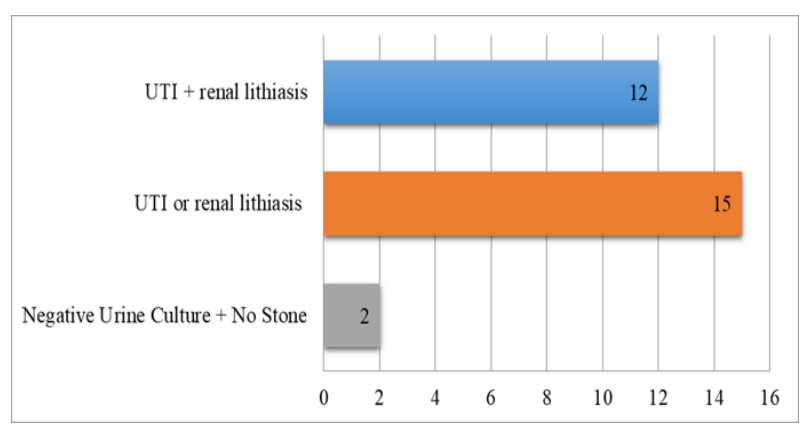

Figure 5. The association of urinary tract infections (UTI) and renal lithiasis in the study group

Our study limitations reside in the retrospective observational nature, the lack of standardized protocol, the progression of the chronic renal disease after the surgical treatment that could not been demonstrated and the low number of cases presented in the study in accordance with the disease prevalence.

It is generally accepted that XGP is caused by a combination of diseases which includes obstructive lithiasis and chronical infections (5). Persistent stasis yields recurrent infections with subsequent coagulative necrosis and destruction of the renal parenchyma. In our study, renal lithiasis was found in 21 cases (72.41\%), which is a strong argument to support the etiopathogenic theory, but we also enrolled 2 patients in which no urinary tract infection or renal calculi were found.

The inflammatory process affects the whole kidney, the focal forms being extremely seldom discovered (1820). Owing to its heterogeneous appearance, XGP can easily be confused with renal cell carcinoma and/or infiltrating urothelial carcinoma of the renal pelvis. There are no findings to support the idea of a bilateral disease, and no predilection for one side only, the percentages 
being almost equal for both left or right sides (7). In this study, we had 16 cases of xantogranulomatous pyelonephritis located on the right side $(55.17 \%)$, but the number of cases and the low percentage cannot support the predominance of this side.

The treatment for XGP is surgical, including open or laparoscopic nephrectomy. Because of the clinical and paraclinical exam, preoperative care should be considered, and it often includes antibiotics and renal drainage (by means of nephrostomy or JJ stent), in combination or separately (21). The authors of a study describe renal drainage using nephrostomy in $77.8 \%$ of the overall 30 cases (2).

The preoperative treatment consisted only in antibiotics in 13 cases $(44,82 \%)$, while in more than a half of the cases $(55.17 \%)$ it was followed by drainage: 13 patients $(44.82 \%)$ with percutaneous nephrostomy and 3 patients $(10.34 \%)$ with JJ stent.

Regarding the surgical approach, open nephrectomy was performed in 21 cases $(72.41 \%)$, similar to the report of a study which analyzed nephrectomy in inflammatory renal disease in Brazil (22). Laparoscopic nephrectomy was performed in 7 cases $(24.13 \%)$ and partial nephrectomy was the treatment of choice in only one case $(3.44 \%)$.

The laparoscopic treatment was frequently disputed, but some studies describe that a good experience in laparoscopy can make this kind of intervention possible also in xantogranulomatous pyelonephritis (23). Laparoscopic nephrectomy for XGP is complicated and more technically demanding than the laparoscopic nephrectomy for noninfectious etiologies (24). For the novice laparoscopist, however, the open approach should remain the approach of choice.

Postoperative blood tests revealed anemia in 25 cases (86.2\%), leukocytosis in 12 cases $(41.37 \%)$ and the presence of kidney failure (eGFR $<60 \mathrm{~mL} / \mathrm{min} / 1.73 \mathrm{~m}^{2}$ ) in 13 patients $(44.82 \%)$.

The examination of the excisional specimen (postnephrectomy) revealed the presence of Xanthogranulomatous pyelonephritis, with characteristic chronic inflammatory infiltration and lipid-laden macrophages in all 29 cases - Figure 6. This is in conformity with the results of the research conducted by Arvind and co. $(25,26)$. The pathological examination revealed the presence of XGP in only 23 cases (79.31\%), but it revealed the presence of the XGP simultaneous with renal carcinoma in six cases $(20.68 \%)$.

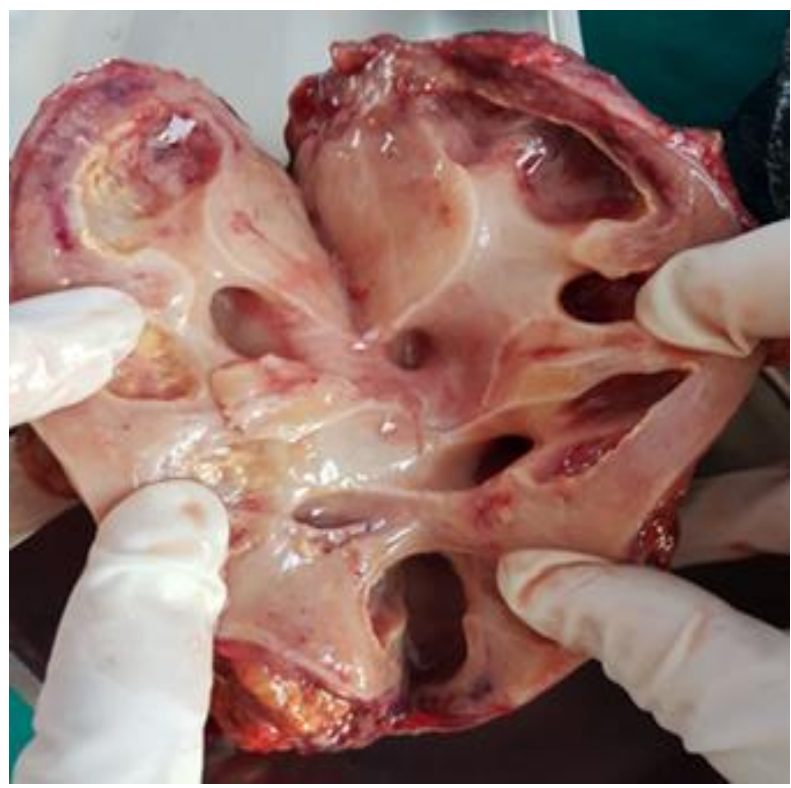

Figure 6. The macroscopic evaluation of the post-nephrectomy specimen

\section{Conclusions}

Our study succeeded in evaluating the demographic, clinical, paraclinical, surgical and histological characteristics of this series of patients. Moreover, the results of the study were compared with the data from other studies. Xanthogranulomatous pyelonephritis affects mostly women (a W:M ratio up to 6:1) aged between 40 and 70 years.

The main symptoms are flank pain and fever, occasionally patients can be asymptomatic. Blood laboratory tests reveal mainly anemia, leukocytosis and kidney failure. The most frequent microorganism found in urine was E. Coli. The treatment was surgical (nephrectomy) in most cases, associated with antibiotic therapy. Antibiotics alone cannot control the disease, but associated with surgical therapy, they can prevent preand postoperative complications.

The diagnosis of certainty is mandatory to be pathological, which is useful not only in the confirmation of the disease, but also in the evaluation of its coexistence with renal carcinoma.

\section{Conflict of interest disclosure}

There are no known conflicts of interest in the publication of this article. The manuscript was read and approved by all authors. 


\section{Compliance with ethical standards}

Any aspect of the work covered in this manuscript has been conducted with the ethical approval of all relevant bodies and that such approvals are acknowledged within the manuscript.

\section{References}

1. Saifullah Khalid, Sufian Zaheer, Samreen Zaheer, Ibne Ahmad, and Mohd Khalid Uber eigentumliche Staphylomykosen der Nieren und des pararenalen Bindegewebes. South Asian J Cancer. 2013; 2(1): 4. DOI: $10.4103 / 2278-330 X .105863$

2. Kuo CC, Wu CF, Huang CC, Lee YJ, Lin WC, Tsai $\mathrm{CW}, \mathrm{Wu} \mathrm{VC}$, Chen YM, Wu MS, Chu TS, Wu KD. Xanthogranulomatous pyelonephritis: critical analysis of 30 patients. Int Urol Nephrol. 2011; 43(1): 15-22. DOI: 10.1007/s11255-010-9778-8.

3. Dwivedi US, Goyal NK, Saxena V, Acharya RL, Trivedi S, Singh PB, Vyas N, Datta B, Kumar A, Das S. Xanthogranulomatous pyelonephritis: our experience with review of published reports. ANZ J Surg. 2006; 76(11): 1007-9. DOI: 10.1111/j.14452197.2006.03919.x.

4. Diaconu CC, Dragoi CM, Bratu OG, Neagu TP, Pantea Stoian A, Cobelschi PC, Nicolae AC, Iancu MA, Hainarosie R, Stanescu AMA, Socea B. New approaches and perspectives for the pharmacological treatment of arterial hypertension. Farmacia. 2018; 66(3): 408-15.

5. Li L, Parwani AV. Xanthogranulomatous pyelonephritis. Arch Pathol Lab Med. 2011; 135(5): 671-4. DOI: 10.1043/2009-0769-RSR.1.

6. Loffroy R, Guiu B, Watfa J, Michel F, Cercueil J, Krausé D. Xanthogranulomatous pyelonephritis in adults: clinical and radiological findings in diffuse and focal forms. Clin Radiol. 2007; 62(9): 884-90. DOI: 10.1016/j.crad.2007.04.008.

7. Al-Ghazo MA, Ghalayini IF, Matalka II, Al-Kaisi NS, Khader YS. Xanthogranulomatous pyelonephritis: analysis of 18 cases. Asian J Surg. 2006; 29(4): $257-$ 61. DOI: 10.1016/S1015-9584(09)60099-3.

8. Ho CI, Wen YK, Chen ML. Xanthogranulomatous pyelonephritis successfully treated with antibiotics only. J Chin Med Assoc. 2008; 71(12): 643-5. DOI: 10.1016/S1726-4901(09)70008-5.

9. Petca R, Popescu R, Petca A, et al. Clinical and pathological features of Xantogranulomatous Pyelonephritis: Single centre experience over 5 years. Eur Urol Suppl. 2017; 16(11): e2951.
10. Mazilu L, Niculescu Z, Suceveanu AI, Suceveanu AP, Tofolean D, Adam T. Ethical aspects of communication with cancer patients. Revista Romana de Bioetica. 2010; 8(3): 181-8.

11. Braticevici B, Petca R, Petrescu A, Jinga V, Ionita L. Incidentally detected prostate cancer in patients undergoing radical cystoprostatectomy. Rom Biotechnol Lett. 2014; 19(1): 9051-7.

12. Petca RC, Popescu RI, Boț M, Veduța A, Petca A. The role of ultrasound in diagnosis and management in renal colic during pregnancy. Proceedings of the 6th Congress of the Ultrasound Society in Obstetrics and Gynecology; 2018; Bucharest, Romania; 2018; 47884.

13. Motofei IG, Rowland DL, Popa F, Bratucu E, Straja D, Manea M, Georgescu SR, Paunica S, Bratucu M, Balalau C, Constantin VD. A Pilot Study on Tamoxifen Sexual Side Effects and Hand Preference in Male Breast Cancer. Arch Sex Behav. 2015; 44(6): 1589-94. DOI: 10.1007/s10508-015-0530-4

14. Totu EE, Manuc D. Multisensor for Clinical Analysis with Impact on Public Health Evaluation. Revista de Chimie 2008; 59(9): 947-51.

15. Leoni AF, Kinleiner P, Revol M, Zaya A, Odicio A. Xanthogranulomatous pyelonephritis: Review of 10 cases. Arch Esp Urol. 2009; 62(4): 259-71.

16. Kim SW, Yoon BI, Ha US, Sohn DW, Cho YH. Xanthogranulomatous pyelonephritis: clinical experience with 21 cases. J Infect Chemoter. 2013; 19(6): 1221-4. DOI: 10.1007/s10156-013-0611-z.

17. Goodman M, Curry T, Russell T. Xanthogranulomatous pyelonephritis (XGP): a local disease with systemic manifestations. Report of 23 patients and review of the literature. Medicine. 1979; 58(2): 171-81.

18. Zorzos I, Moutzouris V, Korakianitis G, Katsou G. Analysis of 39 cases of xanthogranulomatous pyelonephritis with emphasis on CT findings. Scand $J$ Urol Nephrol. 2003; 37(4): 342-7.

19. Siddappa S, Ramprasad K, Muddegowda MK. Xanthogranulomatous pyelonephritis: a retrospective review of 16 cases. Korean J Urol. 2011; 52(6): 4214. DOI: $10.4111 / \mathrm{kju} .2011 .52 .6 .421$.

20. Pantea-Stoian A, Piţuru SM, Hainăroşie R, Andronache LF, Ginghină O, Serafinceanu C. Testosterone therapy, new opportunities in diabetes mellitus. Farmacia. 2018; 66(1): 1-7.

21. Bratu OG, Marcu RD, Socea B, Neagu TP, Diaconu CC, Scârneciu I, Turcu FL, Rădăvoi GD, Brătilă E, Berceanu C, Spînu AD. Immunohistochemistry 
particularities of retroperitoneal tumors. Revista de Chimie 2018; 69(7): 1813-6.

22. Marcu RD, Spînu AD, Socea B, Bodean OM, Diaconu CC, Vasilescu F, Neagu TP, Bratu OG. Castleman's disease - clinical, histological and therapeutic features. Revista de Chimie. 2018; 69(4): 823-30.

23. Tobias-Machado M, Lasmar MT, Batista LT, Forseto Jr PH, Juliano RV, Wroclawski ER. Laparoscopic nephrectomy in inflammatory renal disease: proposal for a staged approach. International Braz J Urol. 2005; 31(1): 22-8. DOI: 10.1590/S1677-5538.IBJU.2017.0363.

24. Rosoff JS, Raman JD, Del Pizzo JJ. Feasibility of laparoscopic approach in management of xanthogranulomatous pyelonephritis. Urology. 2006; 68(4): 711-4. DOI: 10.1016/j.urology.2006.04.031.

25. Judea-Pusta CT, Mutiu G, Pascalau AV, Buhas CL, Ciursas AN, Nistor-Cseppento CD, Bodea A, Judea AS, Vicas RM, Dobjanschi L, Pop OL. The importance of the histopathological examination in lethal acute intoxication with ethylene glycol. Case report. Rom J Morphol Embryol. 2018; 59(3): 965 - 9. 26. Arvind NK, Singh O, Ali Q, Gupta SS, Sahay S. Laparoscopic nephrectomy in xanthogranulomatous pyelonephritis: 7-year single-surgeon outcome. Urology. 2011; 78(4): 797-801. DOI: 10.1016/j.urology.2011.05.062. 